\title{
EFECTOS HEGEMÓNICOS: NEOLIBERALISMO Y PRÁCTICA PARTIDARIA EN EL PERONISMO DE CÓRDOBA DURANTE LA DÉCADA DE 1990
}

\author{
Juan Manuel Reynares ${ }^{l}$
}

\begin{abstract}
RESUMEN
En este artículo pretendemos abrir el espacio para una discusión con aquellos estudios que han analizado el pragmatismo y la corrupción, en tanto características centrales de la realidad política argentina de fines del siglo XX, como fenómenos autónomos. Para ello, y en base al análisis de fuentes provenientes del peronismo de la provincia de Córdoba, sostenemos que la corrupción en tanto problema a ser denunciado públicamente se constituyó como un significante privilegiado de la línea política del peronismo cordobés durante los noventa en la propia disputa partidaria. Nos proponemos demostrar que ello responde a un efecto de la sobredeterminación del discurso hegemónico del neoliberalismo. La corrupción aparece como un hecho a ser denunciado y criticado al momento en que la práctica partidaria comienza a ser interpretada desde una lógica empresarial de mercado.
\end{abstract}

Palabras clave: Corrupción. Neoliberalismo. Lógica empresarial. Peronismo. Córdoba.

\footnotetext{
${ }^{1}$ Doctorando en Ciencia Política por el Centro de Estudios Avanzados de la Universidad Nacional de Córdoba, con beca interna de finalización de doctorado otorgada por CONICET. Docente en la Universidad Nacional de Villa María, Argentina. Dirección de e-mail: juanmanuelreynares@hotmail.com
} 


\title{
HEGEMONIC EFFECTS: NEOLIBERALISM AND PARTY PRACTICE IN PERONISM FROM CÓRDOBA DURING THE NINETIES
}

\begin{abstract}
In this paper we hope to open up a discussion with those studies that have analyzed pragmatism and corruption, as central features of the Argentinian political reality at the end of $20^{\text {th }}$ century, in terms of autonomous phenomena. In order to do this, based on the analysis of sources from the peronism from Córdoba during the nineties, we sustain that corruption as a problem to be publicly condemned was set as a privileged signifier of the peronist political line amidst the party struggle itself. We would like to demonstrate that this responds to an effect of the hegemonic neoliberal discourse. Corruption emerges as a fact to be condemned as the party practice starts to be interpreted from a market-centered enterprise logic.
\end{abstract}

Keywords: Corruption. Neoliberalism. Enterprise logic. Peronism. Córdoba.

\section{INTRODUCCIÓN}

$\boldsymbol{U}$

a práctica política de los años de 1990 en la Argentina ha sido caracterizada, en el marco más general de la denominada crisis de representación, por el pragmatismo y la corrupción. Como veremos en el primer apartado, estos fenómenos han sido estudiados como procesos que incidieron en la forma de hacer política a partir de ciertas transformaciones exógenas. De esa manera, el pragmatismo sería el efecto de la institucionalización partidaria o la dependencia de los recursos públicos, entre otros (LEVITSKY, 2005; MARTUCCELLI; SVAMPA, 1997), mientras la corrupción se ha planteado como una reacción a los escándalos hechos públicos durante los últimos años de la gestión presidencial de Carlos Menem (PEREYRA, 2013).

En nuestro caso, pretendemos abrir el espacio para una discusión con aquellos estudios que han analizado como fenómenos autónomos los cambios en la organización y la práctica partidaria bajo el signo del pragmatismo, como así también la emergencia y tematización de la corrupción. Nos proponemos mostrar que ambas definiciones adquieren sentido al interior de un proceso más general de hegemonización del discurso neoliberal, que tuvo implicancias significativas para el devenir identitario de los actores políticos de la época. 
Con base en el análisis de fuentes provenientes del peronismo de la provincia de Córdoba sostenemos que la corrupción, en tanto problema a ser denunciado públicamente, se constituyó como un significante privilegiado de la línea política del peronismo cordobés durante la década de 1990, es decir, emergió en la propia disputa partidaria, y no como reacción a las "demandas ciudadanas" que surgieron en esa década. En términos más específicos, consideramos que la corrupción aparece como un hecho a ser denunciado y criticado al momento en que la práctica partidaria, la movilización y definición de solidaridades internas al partido, comienzan a ser interpretadas desde una lógica típica del manejo empresarial de una organización.

Para ello, desde el segundo apartado analizaremos estos desplazamientos de sentido entre comienzos y finales de los años de 1990. Nos abocaremos a ese ejercicio a través de una comparación diacrónica de dos momentos de discusión partidaria, durante 1990 por un lado y a partir de 1992, por el otro. Allí podremos observar cómo la progresiva hegemonización neoliberal tuvo profundos efectos en la forma en que los propios actores partidarios interpretaban públicamente su accionar al interior del partido, y cómo la denuncia y crítica en torno a la corrupción pasó a estructurar la discusión política.

\section{LA PRÁCTICA PARTIDARIA PERONISTA Y EL FIN DE SIGLO}

Existen variados acercamientos al problema de la militancia dentro del peronismo y sus transformaciones en los últimos años del siglo XX, sobre todo bajo la presidencia de Menem. ${ }^{2}$ En el conjunto de las ciencias sociales y desde distintos presupuestos analíticos, se ha considerado esta etapa bajo la categoría del pragmatismo. Martuccelli y Svampa (1997) han analizado la militancia del peronismo y el menemismo y planteado tres tipos de militante. Entre las décadas de 1940 y 1960 predominó el militante sindical peronista, mientras que el militante revolucionario, por su parte, fue típico de los años setenta.

En esta clasificación, el militante pragmático corresponde al período posterior al retorno de la democracia, cuando se conjugó el vacío generacional creado por la represión dictatorial con la progresiva racionalización e

\footnotetext{
${ }^{2}$ La pregunta por las transformaciones del peronismo desde el retorno a la democracia ha sido formulada por numerosos estudios tanto a nivel nacional como subnacional, desde diversas perspectivas analíticas más allá de aquellas miradas en las que profundizamos a lo largo de este artículo (ABOY CARLÉS, 2001; AUYERO, 2001; BARROS, 2002; BORÓN et al. 1995; FERRARI, 2008; MUSTAPIC, 2002; PUCCIARELLI, 2011; SIDICARO, 2002, entre otros).
} 
institucionalización del partido. Ello conllevó, desde múltiples aspectos, a que "todas las críticas coinciden en la rentabilización de la actividad política [...] los incentivos selectivos materiales (y de estatus) remplazan a los incentivos colectivos de identidad, sobre todo los que aluden al "proyecto"' (MARTUCCELLI; SVAMPA, 1997, p. 149). Esta transformación trajo aparejada una serie de características propias del militante peronista de esta etapa, que los autores reunieron en "su profesionalización económica y su pragmatismo ideológico. Actitud que cambia la sensibilidad hacia las alianzas políticas" (MARTUCCELLI; SVAMPA, 1997, p. 150).

Desde una perspectiva analítica diferente, S. Levitsky (2005) estudió la estructura partidaria del peronismo desde los años de 1980 como una "desorganización organizada", que permitió la inserción territorial del peronismo en momentos en que la predominancia sindical en el sostenimiento del partido se vio remplazada por la dependencia clientelista y la utilización de recursos públicos. El autor partió de considerar un intercambio entre los líderes partidarios y los punteros en que el alto grado de autonomía de estos últimos echaba por tierra la idea de una relación unilineal entre la línea política del dirigente y las prácticas partidarias territoriales. Así, los jefes barriales podían sostener la preferencia por la intervención estatal mientras que el gobierno nacional del mismo signo partidario implementaba medidas macroeconómicas de apertura a los mercados internacionales. Antes que por una identificación política, el trabajo de los militantes y afiliados parecía estar marcado por una relación pragmática, calculada, y despojada de matices ideológicos (LEVITSKY, 2001). Este autor sostuvo su análisis sobre el presupuesto de que la actividad política como tal se agota en su dimensión estratégica, llevada a cabo por actores plenamente conscientes de sí. Así, la desorganización de la estructura partidaria beneficiaría a ambos extremos de la relación de intercambio, líder y agencias territoriales.

Para Levitsky, la figura típica al interior de la organización peronista es la del "pragmático", como describían Martuccelli y Svampa a una de las posibles tipologías de militante peronista. Todas estas figuras comparten una común reducción de la militancia peronista a la categoría de "solucionador de problemas", donde adquiere sentido la profesionalización y mercantilización del puntero estereotipado. Ahora bien, ¿cómo comprender el advenimiento de ese militante pragmático durante los años de 1990, al mismo tiempo que se verifica la introducción del dinero como principio estructurante de la organización y prácticas partidarias?

Ninguna de las posibles respuestas que plantean estos autores toma en cuenta la dimensión ideológica por la que cada una de estos fenómenos se vuelve 
posible. Por nuestra parte, al considerar los cambios en la práctica partidaria como expresión de una progresiva sobredeterminación neoliberal —es decir, de la expansión de un discurso que promueve la interpretación de las prácticas partidarias como prácticas empresariales, individualizadas en un marco de pretendida transparencia social一, éstos no aparecen como fenómenos naturales o propios de dinámicas autónomas de racionalización o de profesionalización. Más bien, estas transformaciones emergen como prácticas cuyo sentido se inscriben en horizontes discursivos particulares y conflictivamente constituidos. ${ }^{3}$

\section{El PERonismo de Córdoba A PRincipios de 1990}

El Partido Justicialista (PJ) en Córdoba finalizaba la década de 1980 en un escenario de velada disputa interna. Su dirigencia provincial estaba enrolada en la denominada Renovación Peronista, una línea interna surgida a mediados de esa década que abogaba por el reordenamiento democrático de la organización partidaria y la defensa del partido en la consolidación institucional del país. Su principal líder y presidente del Consejo Provincial del PJ era José Manuel De la Sota, quien había sido candidato a gobernador en 1987. Se había enfrentado como precandidato a vicepresidente junto con el dirigente de la provincia de Buenos Aires, Antonio Cafiero, a la fórmula que resultaría elegida para la presidencia argentina en 1989, formada por Carlos Menem y Eduardo Duhalde. De esta manera, la dirigencia provincial del PJ cordobés era oposición interna de la nueva jefatura nacional, organizada alrededor del reciente presidente electo (ALTAMIRANO, 2004; CLOSA, 2010). Si bien De la Sota apoyó públicamente la candidatura y la nueva gestión de Menem, hacía explícita la necesidad de preservar un "ámbito democrático de convivencia", con respeto al "derecho de disenso" (LVI, 02/10/1990, p.9A). Al mismo tiempo, la llegada de Menem a la presidencia motivó la emergencia, o el reforzamiento, de sectores internos opositores a la Renovación, quienes comenzaron a disputar la representación del justicialismo provincial haciendo uso de los recursos provenientes de la administración nacional y sosteniendo su enunciación en su capacidad de interpretar la palabra

\footnotetext{
${ }^{3}$ En este artículo entenderemos al neoliberalismo más allá de su delimitación como un set dado de políticas macroeconómicas. Así el neoliberalismo funge como superficie de inscripción para heterogéneos proyectos políticos de diverso alcance espacio-temporal (LARNER, 2000). Emerge así como un discurso político, y como tal inmerso en una dinámica conflictiva y hegemónica (LACLAU; MOUFFE, 2004; LACLAU, 2000, 2006), que promueve una específica tecnología de gobierno mediante la cual todos los individuos entran en interacciones sociales a la manera de empresarios de sí mismos (FOUCAULT, 2007; LEMKE, 2006).
} 
del nuevo líder del movimiento, Carlos Menem. De esta manera, al interior del PJ cordobés se ponía en discusión qué era necesario hacer para apoyar al gobierno nacional.

En este contexto de apoyo crítico, a principios del año 1990, un grupo de ocho diputados nacionales peronistas se alejó de la bancada oficialista enarbolando una fuerte crítica a la política económica, social y militar del nuevo gobierno, lo que provocó discusiones internas sobre su futuro dentro del Partido Justicialista. La posición de Antonio Cafiero, presidente del Consejo Nacional y máxima autoridad partidaria, fue la de dar lugar al disenso interno, sin echarlos del partido, planteando la necesidad de un partido rico en discusión y ejemplo de democracia interna.

En Córdoba hubo repercusiones de este caso. Juan Carlos Maqueda y Mario Blanco, diputados provinciales de la línea renovadora peronista, consideraban que:

[...] la alianza del gobierno nacional con algunos sectores liberales y conservadores, ante la falta de debate previo, ha producido una crisis de identidad en el peronismo [...]. Defendemos el derecho a disentir como lo hacen los diputados nacionales del llamado "Grupo de los Ocho", más allá de compartir o no sus expresiones, máxime cuando las políticas que se están implementando no figuran en la plataforma electoral ni fueron votadas el 14 de mayo de 1989 [...] [nos inquieta] el avance de sectores autoritarios, lo que debe llevarnos a fortalecer el frente democrático, bajo la convicción de que, lejos del facilismo, la democracia, la libertad y el crecimiento son difíciles, pero son la única alternativa de la humanidad.

Finalmente, el texto se volvía crítico con algunas líneas internas del peronismo local:

[...] [deploramos] la actitud de algunos sectores, que entienden que apoyar al Presidente significa ser obsecuentes y callan verdades que el pueblo nos grita en las calles, instaurando un estilo de complicidad con los errores que no se compadecen con nuestra mejor historia, con nuestro compromiso militante ni con la sociedad sincerada, abierta, transparente y pluralista que pretendemos conseguir (LVI, 08/02/1990, p. 5A. Cursivas agregadas). 
El texto hecho público reconocía así dos problemas con una misma causa: por un lado las decisiones políticas a nivel nacional, y por el otro, la obsecuencia de sectores locales. En ambos, la razón se ubicaba en la crisis de identidad del peronismo. Maqueda y Blanco justificaban el disenso entre las propias filas de su partido a partir del carácter erróneo de las políticas nacionales para lidiar con la crisis, como así también en la incoherencia que surgía entre el mensaje de campaña, las medidas concretas y las alianzas estratégicas del gobierno menemista. ${ }^{4}$ Los autores reivindicaban el disenso como el mejor modo de apoyar la gestión nacional, ya que así se era leal a lo expresado en las calles. La obsecuencia era, muy por el contrario, cómplice en los errores que estaba cometiendo Menem. De esa manera, se ponían en juego distintas lecturas sobre el peronismo. Maqueda y Blanco defendían un peronismo articulado a las nociones de democracia y pluralismo, donde la crítica de los diputados nacionales era el modo de colaborar con la resolución de los problemas coyunturales, sin relegar al mismo tiempo la representatividad de los sectores populares, de la calle.

Fuera de la dirigencia partidaria, las críticas planteadas por "el grupo de los 8" encontraron resistencia en otros sectores internos locales. Leonor Alarcia, dirigente de larga data dentro del peronismo, autodenominada vocera de Menem en Córdoba y diputada nacional, consideraba a los diputados críticos como "grupúsculo altamente intelectualizado y de escasa representatividad social" (LVI, 08/02/1990, p.5A), y exigía a las autoridades partidarias que se les impartieran medidas disciplinarias. Generalmente, esta escasa representatividad social era planteada como crítica para aquellos peronistas "de saco y corbata", para los renovadores que no poseían la práctica peronista tradicional de visitar "los barrios carenciados de la provincia" (LVI, 09/02/1990, p.4A). El peronismo se comprendía así en torno a la imagen de aquél que caminaba las calles, que conocía a los humildes, que solucionaba sus demandas. Ésa es la "concepción ideológica y doctrinaria netamente peronista" (ídem) que sustentaba, en palabras de Alarcia, la gestión peronista de Menem.

La dirigente hacía uso de las palabras del entonces presidente, quien había consolidado el lazo representativo por fuera de la figura institucional del partido a lo largo de su campaña como pre-candidato y luego al frente de la fórmula

\footnotetext{
${ }^{4}$ Dicha incoherencia se refería al denominado "giro neoliberal" que realizó Menem una vez en la presidencia respecto de su mensaje de campaña, que había estado centrado en mensajes tradicionales del bagaje peronista como la "revolución productiva" y el "salariazo" (BORÓN et al., 1995, entre otros), al establecer en sus primeros meses de gestión una alianza con sectores concentrados de la economía argentina y promover reformas estructurales de ajuste y privatización de empresas estatales.
} 
presidencial, dando forma a un recorrido kilométrico de contacto directo con el electorado, con preeminencia entre los sectores carenciados. La emergencia del menemismo se había caracterizado, en parte, por el acceso inmediato de Menem con los dirigentes barriales, y con las "bases peronistas", desarrollando una extensa campaña para las internas de 1988 y para las generales de 1989 (BARROS, 2002, p. 133). Ese contacto directo, ese caminar los barrios, otorgaba una legitimidad al dirigente peronista que respondía a la tradición peronista donde la representación se reforzaba en la igualdad entre las bases y el político. Menem resolvía problemas en la gestión conociéndolos de primera mano. Así mismo, el candidato a presidente en 1988 criticaba a los renovadores por ser "peronistas de saco y corbata", que practicaban un "sectarismo ilustrado". Se observaba allí una caracterización del pueblo peronista como inculto y práctico, que Menem, en la figura del líder, venía a representar.

Los sectores menemistas de Córdoba retomaban estos significantes en la disputa interna y los contraponían al argumento de Maqueda y Blanco, considerando que el peronista verdadero seguiría recorriendo los barrios y solucionando los problemas de desempleo y precarización social que resultaran de las medidas de ajuste y reforma que fueran necesarias. La única posibilidad de representatividad social estaba entonces en la militancia barrial, territorial, que se volvía así pasible de ser articulada al interior de un discurso nacional que proponía desregulación y apertura económica. La dimensión tradicional del peronismo como solucionador local de problemas sociales era rearticulada a partir de los desplazamientos subjetivos que suponían las medidas del gobierno nacional. Ella es la condición de posibilidad para que los sectores internos del peronismo cordobés que defendían la gestión menemista pudieran erigirse en guardianes de la doctrina y criticaran los renovadores críticos por no representar a la sociedad.

La disputa dentro del peronismo cordobés, en 1990, de lo que suponía una práctica partidaria permite ver esos desplazamientos de sentido y la progresiva articulación ideológica que toma forma a través de ellos. Tanto Alarcia como Maqueda y Blanco discutían en torno a la representatividad de las bases peronistas. Estos últimos cifraban dicho lazo privilegiado con el pueblo en el pluralismo y la apertura, es decir que interpretaban al peronismo desde el relato democrático hegemónico del gobierno alfonsinista (ABOY CARLÉS, 2001; BARROS, 2002). ${ }^{5}$

\footnotetext{
${ }^{5}$ Luego de la derrota de 1983, el espacio público nacional estuvo estructurado en torno a la defensa irrestricta de las instituciones democráticas, encarnada en la palabra de Alfonsín, primer
} 
La práctica partidaria se volvía objeto de discusión y allí se enfrentaban dos lecturas, un peronismo de a pie y práctico, otro abierto a la discusión e institucionalmente plural, que mostraban los efectos de dos superficies ideológicas de inscripción distintas, aún en pugna. Desde la Renovación, si el partido era el responsable institucional de la democratización de una sociedad que todavía sufría las heridas de un pasado autoritario, debía darse máxima importancia a la representación de las diferencias internas. Desde el menemismo en cambio, si las dificultades materiales eran una deuda de la transición, el apoyo al líder nacional era indispensable, y el rol del peronismo se ubicaba en la resolución de tales problemas, sin que revistiera mayor importancia la discusión por las razones de su permanencia y acrecentamiento. El conflicto entre Maqueda y Blanco, por un lado, y Alarcia por el otro, estaba sobredeterminado por la disputa entre la Renovación Peronista y la tradición movimientista del peronismo que Menem había articulado en su discurso enfrentándose al elitismo ilustrado de los renovadores como De la Sota en Córdoba. De esa manera, las diferencias se estructuraban en torno al apoyo racional, plural, o la obsecuencia y el verticalismo. En ninguno de los dos casos, ni el dinero o la corrupción eran utilizados como una forma de deslegitimar al adversario interno.

Sin embargo, entrada la última década del siglo XX, la principal denuncia entre los propios dirigentes partidarios se centrará en la corrupción y el uso espurio de los recursos estatales en la movilización partidaria. Entre la discusión entre renovadores y menemistas por un lado, y las denuncias internas cruzadas sobre el origen de los fondos para la movilización por otro, consideramos que media una transformación subjetiva que se vuelve necesario subrayar. Ello nos permite introducir entonces una interrogante por los efectos que el discurso neoliberal tuvo en los partidos políticos, y de manera específica, qué implicó este proceso en la trayectoria subjetiva del peronismo cordobés, donde el pragmatismo de la militancia, el uso del dinero y la introducción de la corrupción como temática política aparecieron anudados de manera conflictiva y compleja.

presidente argentino luego de la dictadura militar, que gobernó entre 1976 y 1983. Había un pasado antidemocrático al que no se debía regresar (ABOY CARLÉS, 2001; BARROS, 2002; ALTAMIRANO, 2004). En ese contexto, los sectores renovadores provinciales promovieron la elección de las autoridades partidarias mediante elecciones internas. La discusión sobre la organización institucional giraba así entre un eje "renovador" que articulaba la defensa de la democracia con la reivindicación de la forma - partido, y otro eje "ortodoxo" que sostenía significantes propios del discurso más tradicional del peronismo como lo eran el verticalismo al interior del movimiento (CLOSA, 2010; REYNARES, 2012a). 


\section{LA MILITANCIA RENTADA EN EL PERONISMO CORDOBÉS}

Una vez que hemos recuperado algunos estudios sobre los cambios en la práctica partidaria a fines del siglo XX, y planteado el escenario institucional en que estas transformaciones tienen lugar en el peronismo de Córdoba, nos interesa rastrear la sobredeterminación ideológica de dichas transformaciones, y de allí su estrecha relación con la emergencia de la corrupción como un problema político interno.

Es claro que los recursos materiales son necesarios en la actividad partidaria, y que incluso esa dimensión es una de las características de los partidos políticos desde su emergencia en los regímenes políticos democrático liberales de inicios del siglo XX (LEIRAS, 2007; PANEBIANC0, 2009; SARTORI, 1987). Sin embargo, lo que nos interesa remarcar es la presencia del dinero como estructurador de la dinámica partidaria del peronismo cordobés a partir del retorno de la democracia en la Argentina y la emergencia de la Renovación Peronista, en estrecho contacto con la hegemonización del discurso neoliberal. En algún momento, entre el final de la década de 1980 y principios de 1990, las actividades propias del partido, la militancia y la dirigencia, parecen sufrir una transformación de amplios alcances, en tanto el dinero comienza a asumir predominancia en la definición de la acción partidaria. De allí que,

Lo que siempre se dice, y lo dice el peronismo ortodoxo, y Bercovich [líder del peronismo cordobés antes de la Renovación, representante de sectores ortodoxos]... esto es... es polémico lo que voy a decir, es que... entró con la renovación un discurso de profesionalización de la político, y esto necesariamente vino de la mano de la plata. Siempre los sectores ortodoxos culparon, responsabilizaron, a De la Sota de haber metido plata. Yo diría que lo que aparece, después, es la plata [...] Ese fue un proceso que terminó matando la militancia, terminó vaciando el contenido del peronismo [...] (Entrevista personal con ex-dirigente peronista, 16/11/2011).

En el marco de estas expresiones, lo que resuena allí es la reunión de dos procesos simultáneos: la aparición del dinero y los "negociados", junto al vaciamiento del contenido ideológico y la desaparición de la militancia. Ésta última, a la que se le da el sentido de la conducta abnegada del que participa en política, deja lugar al cálculo desideologizado de individuos que buscan verse 
beneficiados por la inclusión en "la política". ${ }^{6}$ Así, en tanto que la mayor presencia de recursos materiales a la base de la movilización partidaria es efecto de la sobredeterminación del discurso neoliberal, se diluye la diferenciación ideológica entre las líneas internas. Al mismo tiempo, se comienza a esgrimir el argumento de la corrupción en una clave ética y universalista, desde el interior del aparato partidario.

De esta manera nos alejamos de aquellos análisis que consideran a la denuncia de corrupción como un fenómeno autónomo que surge a inicios de los años de 1990, a través de diversos espacios de denuncia, y que hizo erupción a fines de la misma década como reacción a los sucesivos escándalos de la administración menemista (PEREYRA, 2013). Más bien, sugerimos que esos escándalos adquieren magnitud pública a partir de significantes disponibles y creíbles, asiduamente articulados por los propios actores que encarnan el discurso neoliberal, sobre la transparencia de la política y el mal uso de los recursos estatales.

La sobredeterminación neoliberal se vuelve presente en una miríada de efectos: en las prácticas partidarias, en la pretendida desideologización bajo un manto neoliberal, y en la introducción de la corrupción como un significante creíble en el trasfondo de una comprensión de la política como ámbito transparente de traslación de demandas sociales al interior del aparato estatal.

\section{LÓGICA EMPRESARIAL Y PRÁCTICA PARTIDARIA}

Como hemos planteado más arriba, a mediados de 1990, en el marco de incertidumbre de los primeros meses de la administración menemista, distintos sectores internos habían discutido sobre la representatividad del partido en los territorios locales. Luego de la derrota en las elecciones provinciales de 1991, las líneas internas que disputaban la representación del peronismo eran al menos

\footnotetext{
${ }^{6}$ El hecho de que existieran múltiples motivaciones en la práctica política, donde la estrategia ligada al manejo de recursos públicos es sólo una de ellas, no pasa desapercibido para la mayoría de los entrevistados que evitan caer así en lugares "utópicos" o "románticos". Así, un militante que había participado de la agrupación Transvasamiento Generacional en los años de 1970 , y que en julio de 1990 renunció al Partido Justicialista por fuertes desacuerdos con la administración menemista consideraba que "en los setenta no había tipos que fueran a pedir cargos... no había masivamente intencionalidad de ser legislador, se aceptaba al más capaz... había idea de reparto, de abrir el juego... yo creo que siempre existieron los negocios, pero siempre había un límite... estaba más o menos dentro de lo legítimo, ahora se ha perdido todo tipo de normalidad" (entrevista con ex afiliado y militante del peronismo, 29/10/2013).
} 
cuatro. ${ }^{7}$ El oficialismo local, dirigido por De la Sota, pretendía retener el control del distrito electoral de la Capital provincial y los contactos con líderes municipales. Por su parte, el Ministro de Salud y Acción Social de la Nación, Julio César Aráoz, intentaba ampliar su influencia en el territorio provincial, mostrándose como un funcionario con contacto directo con Presidencia. Mientras tanto, la ya mencionada diputada nacional L. Casari de Alarcia y el Movimiento Córdoba Justicialista — formado por algunos intendentes como Jorge Bucco de la ciudad de San Francisco, con el apoyo del entonces Ministro de Economía de la Nación, Domingo Cavallo - pretendían, cada uno por su parte, disputar la jefatura del PJ cordobés.

En ese marco, en octubre de 1992 se llevaron a cabo dos actos para conmemorar el Día de la Lealtad peronista. Uno de ellos fue organizado por el Distrito Córdoba del Partido Justicialista (PJ), dirigido por De la Sota, mientras el otro era convocado por Aráoz. El diario provincial, La Voz del Interior, consideraba que este doble llamado a un acto tradicional del peronismo era el puntapié de la campaña interna con vistas a las elecciones legislativas de 1993 (LVI, 16/10/1992, p. 4A). De allí puede asumirse que la estrategia planteada por ambos actores internos era la demostración de fuerzas de base en el territorio de mayor incidencia electoral de la provincia, la ciudad de Córdoba.

La celebración de los dos actos reunió cantidades similares de participantes, unos ocho mil en el acto oficial y siete mil en el que organizaba Aráoz. En las dos ocasiones, los principales oradores enfatizaron la necesidad de la unidad interna del peronismo, e hicieron alusiones a Perón y Eva en el marco del tradicional festejo. Durante los actos, no se marcaron diferencias significativas en los mensajes enunciados, ya que ambos recurrieron a los símbolos tradicionales de Juan Perón y Eva Perón y enfatizaron la necesidad de la unidad partidaria tras el liderazgo nacional de Menem. Tanto el delasotismo como otros interlocutores partidarios criticaron a la organización de Aráoz por el uso de la "dádiva", es decir, la utilización de recursos públicos para la movilización del aparato partidario, "comprando la conciencia de los dirigentes repartiendo prebendas y subsidios" (LVI, 18/10/1992, p. 6A). Incluso Bucco denostaba a sus adversarios porque "fueron dos actos con un mismo estilo de hacer política: la utilización

\footnotetext{
${ }^{7}$ A partir de la progresiva identificación de los dirigentes partidarios con la política llevada adelante por el gobierno nacional, las críticas internas ocuparon lugares cada vez más marginales. En efecto, aquellos militantes y dirigentes que se opusieron al gobierno nacional no pudieron establecer una plataforma de crítica con implicancias electorales o públicas de mayor relevancia.
} 
indiscriminada de los aparatos y la utilización desenfrenada de los recursos económicos" (LVI, 18/10/1992, p. 6A).

La disputa interna parecía entonces comprender específicamente los recursos utilizados para la movilización, compartiendo las distintas posiciones enunciativas una misma gramática, desde una perspectiva universalista y ética. Tanto el "aparato" como la "dádiva" pueden catalogarse como incentivos selectivos que las líneas internas del delasotismo y el araocismo ponían en juego, haciendo uso de los recursos organizacionales a su alcance: la institucionalidad partidaria en el caso del primero, los recursos públicos del Ministerio de Salud y Acción Social de la Nación, el segundo.

Por el contrario, los incentivos colectivos de identidad no eran objeto de disputa y se diluían en una vaga referencia a Perón y en el apoyo al gobierno nacional. La minimización de los componentes ideológicos en la estructuración de fuerzas territoriales partidarias trasladaba los motivos de los conflictos entre líneas internas a cuestiones personales, o las remitían más bien a reivindicaciones morales, tal como la crítica de De la Sota a Aráoz al decir que "la dádiva envilece a quien la da" (LVI, 17/10/1992, p. 4A).

La predominancia de los recursos materiales y la crítica moral muestran un déficit argumentativo en el enfrentamiento interno, donde sólo era importante cuestionar el origen y el uso de los recursos con que Aráoz o De la Sota pretendían construir una red de apoyos territoriales en el distrito Capital. En general, tal "vaciamiento de contenido" podría ser considerado como la señal de una misma identificación neoliberal, esto es, si ambos dirigentes creían en lo mismo, dirían lo mismo. No obstante, no existía sólo un solapamiento de valores e ideas al nivel de cierto contenido ideológico, sino que la poca relevancia de la palabra política se explicaba por efecto de esa misma articulación ideológica.

El hecho de que la disputa intrapartidaria se centrara en la dádiva o el aparato indicaba el modo en que los actores interpretaban la institución cuyo control se disputaban, el Partido Justicialista provincial. La ausencia de discusión política que comenzó a caracterizar la dinámica interna del peronismo cordobés en la década de 1990 muestra la manera en que el discurso hegemónico neoliberal sobredeterminaba el uso de la palabra pública y la vaciaba de sentido. En ese marco, la política y la práctica partidaria como su vehículo se limitaban al conocimiento y uso estratégico del intercambio de recursos en búsqueda de apoyo electoral. La única diferencia relevante entre ambas convocatorias de las líneas internas en ocasión de la celebración del "Día de la lealtad" era la que marcaba los intereses personales de sus líderes y el intercambio de incentivos selectivos 
que hubiesen podido organizar. De allí que las alusiones críticas entre ellos fueran estrictamente personales, y apuntaran al mismo tiempo a la universalidad de los valores públicos.

Lo que sostenemos aquí es que esa práctica, lejos de corresponderse exclusivamente a una racionalidad estratégica intrínseca de los actores políticos, adquiría sentido al interior de una articulación discursiva neoliberal. Era en ese encadenamiento que podían entenderse los términos explícitos en que se desenvolvían las contiendas partidarias, aparentemente desideologizadas, y donde la presentación de ambos portavoces internos tomaba la forma de empresarios ante la competencia electoral. Así, el pragmatismo y la preeminencia de los incentivos selectivos materiales como elementos propios de la dinámica de los dirigentes, adquirían sentido como las características centrales de una lógica empresarial que indicaba la sobredeterminación ideológica del discurso neoliberal sobre la práctica partidaria.

Si bien parece posible asumir la existencia de dos dimensiones centrales en la práctica política, la estrategia por un lado y la identidad por otro, la ideología asume un rol constitutivo en toda organización partidaria. ${ }^{8}$ Por lo tanto, la práctica partidaria no puede pensarse como un núcleo de intercambio que se ve cubierto en un segundo momento por contenidos ideológicos en una u otra dirección. Más bien, las prácticas partidarias están atravesadas por superficies ideológicas en que adquieren sentido de manera más o menos conflictiva (REYNARES 2012b). Por lo tanto, la reducción de la disputa política al enfrentamiento personal entre dirigentes y la interpelación en clave universal de un individuo ético no muestra meramente un vacío ideológico, sino que marca los mismos límites de sentido en que se inserta una práctica.

Ahora bien, la discusión sobre el origen y uso correcto del dinero se vuelve posible en el marco en que la práctica partidaria se comprende como una actividad propia de un empresario, de allí que el planteo de corrupción se articule al discurso neoliberal tras la pretensión de transparencia social que la política viene a distorsionar e interrumpir. De esta manera, las posturas de los actores partidarios internos muestran su identificación con el discurso neoliberal hegemónico en el uso que hacían de la institución partidaria a lo largo de sus

\footnotetext{
${ }^{8}$ Para subrayar el lugar de la ideología en el análisis de los partidos políticos, partimos de algunos estudios sobre partidos políticos y organizaciones partidarias dentro de la amplia bibliografía sobre el tema: Abal Medina (2002, 2004); Panebianco, (2009); Sartori (1987).
} 
prácticas políticas, dentro del cual toma sentido su aceptación de las medidas del gobierno nacional. ${ }^{9}$

Esta preeminencia de los incentivos selectivos, y específicamente de los recursos en dinero, en todos los niveles de la organización partidaria era puesta de relieve por Guillermo Johnson, un extrapartidario que fue candidato a gobernador por el PJ cordobés en 1995. Johnson planteaba que

Durante todo este tiempo [se refiere a la campaña que acababa de terminar con su derrota frente al candidato radical, Ramón Bautista Mestre] advertí que, sobre todo en la Capital, el justicialismo se mercantilizó y eso no puede ser... [hay] punteros y dirigentes que no trabajan sin dinero de por medio (LVI, 18/06/1995, p. 4A).

En el mismo sentido, militantes barriales del peronismo mencionaban que existía "una militancia rentada que no se ocupa de las necesidades de la gente en los barrios... ya no van más en el partido las mismas caras que conocemos todos y que sólo trabajan en beneficio propio [...] (LVI, 18/06/1996, p. 6A).

De esta manera, se remarcaban las transformaciones que supuso el intercambio monetario en la adhesión y movilización de las bases partidarias. En mayo de 1998, dos dirigentes de la Capital, Oraldo Senn y Ricardo Moreno, que estaban enrolados en la estructura que lideraba el intendente de San Francisco, Jorge Bucco, se alejaron de dicha organización. En ese momento, Moreno hizo

\footnotetext{
${ }^{9}$ Situándonos dentro del denominado "giro lingüístico" en las ciencias sociales, rechazamos la noción de un fundamento institucional ya plenamente instituido, sobre el cual se verifican a posteriori prácticas accesorias y secundarias. Frente a ello, sostenemos que nunca hay un uso definido a priori de una regla 0 , lo que aquí es lo mismo, un sistema de reglas configurado en una institución (DERRIDA, 1998; WITTGENSTEIN, 1999). Ese uso, esa práctica, constituye a la institución y lo hace a partir de una sobredeterminación discursiva que es política (LACLAU, 2006). En este caso, que las prácticas partidarias se interpretaran a través de incentivos selectivos y la capacidad individual de los portavoces por atraer mayores apoyos electorales a partir del uso de recursos económicos directos o indirectos, es un efecto discursivo de la sobredeterminación neoliberal y la caracterización de todo individuo como empresario, tanto de sí como en sus ámbitos institucionales. De esta manera, la práctica partidaria no puede pensarse por fuera de los significantes que se ponen en juego para legitimar el accionar de los dirigentes, ya que no hay exterioridad entre el orden de los discursos y el de la acción, sino mutua co-constitutividad, en tanto toda acción adquiere sentido en su inscripción dinámica y conflictiva en un campo de la discursividad parcialmente estructurado por discursos heterogéneos en disputa (LACLAU; MOUFFE, 2004).
} 
explícito que "su paso al costado deja a Bucco sin una estructura en la Capital de 'alrededor de 140 unidades básicas'” (MORENO..., 1998) ${ }^{10}$. Las negociaciones entre dirigentes aludían de forma manifiesta a las unidades básicas y la organización territorial como capital puesto a disposición de un negocio. La propia interpretación de los actores incluía una visión empresarial de su estrategia para el acceso a cargos y recursos estatales. Dicha lógica que sostiene a las prácticas partidarias adquiere sentido al interior de un discurso político que volvía a cada actor partidario un empresario individualizado en la pugna partidaria, entendida como una negociación en que los apoyos territoriales eran ubicados donde pudieran asegurar mayor "rendimiento" electoral.

\section{Algunas nOtas PARA CONClUIR}

La década de 1990 ha sido caracterizada, tanto desde el sentido común como desde algunos de los acercamientos analíticos que hemos rastreado aquí, por la aparición del pragmatismo y la corrupción como problemas centrales de la práctica política. Sin embargo, no ha habido una interrogación sistemática sobre estos significantes en su articulación a un discurso hegemónico que completa su sentido de una manera precaria y conflictiva. Tanto el pragmatismo como la corrupción son interpretados como corolario de procesos estructurales que los determinan de alguna manera, o bien como propios del "aire de época", o incluso como características intrínsecas a la práctica política. Lejos de ello, el análisis de las transformaciones subjetivas del peronismo cordobés muestra cómo la tematización de la corrupción y la expansión de una lógica empresarial en la práctica partidaria son efectos de la sobredeterminación hegemónica de un discurso neoliberal.

La corrupción apareció como elemento estructurante de las denuncias intrapartidarias al mismo tiempo que desaparecían las discusiones internas sobre la mejor organización del partido. Tanto la expansión de la lógica empresarial - esto es, la exacerbación de la dimensión estratégica en la dirigencia y movilización partidaria al mismo tiempo que se subestimaba la disputa de ideas y valores- como la denuncia central de la corrupción en las campañas se volvieron posibles en un horizonte ideológico hegemónico. Éste estaba estructurado, por un lado, por una topografía social que confinaba la política a un carácter secundario, cumpliendo el papel de mero canalizador de demandas, reduciendo la responsabilidad del gobernante al respeto de las formas institucionales. Por el otro

\footnotetext{
${ }^{10}$ Este artículo fue extraído de La Voz del Interior en su versión digital (MORENO..., 1998).
} 
lado, la hegemonía neoliberal promovía la expansión de una subjetividad individualizadora y maximizadora de beneficios, por lo que la actividad de los dirigentes partidarios se confinaba al cálculo y la competencia de empresarios electorales.

En suma, durante la década de 1990 en el peronismo cordobés se consolidó una interpretación de lo que debía hacerse dentro del partido que se demostraba en las denuncias y recursos que daban forma al debate interno y que se configuraba en la identificación con un discurso hegemónico. Ello no implicó la emergencia de efectos absolutamente novedosos, sino que más bien provocó el énfasis en dimensiones constitutivas de cualquier práctica partidaria como lo son la estrategia y el manejo de recursos necesarios para la movilización y organización territorial. El hecho de que sólo se plantease el aspecto económico de la movilización partidaria no responde a una "neutralización ideológica" que dejaría al descubierto el núcleo utilitarista de la política. Por el contrario, es un efecto de la sobredeterminación hegemónica neoliberal que promueve la interpretación de todas aquellas prácticas en que nos involucramos como si éstas tomaran la forma de un intercambio en el mercado.

\section{REFERÊNCIAS}

ABAL MEDINA, Juan Manuel. Elementos teóricos para el análisis de los partidos políticos. In: CAVAROZZI, Marcelo; ABAL MEDINA, Juan Manuel (Comp.). El asedio a la política. Los partidos latinoamericanos en la era neoliberal. Rosario: Homo Sapiens, 2002.

ABAL MEDINA, Juan Manuel. Los partidos políticos ein mal necesario? Buenos Aires: Capital Intelectual, 2004.

ABOY CARLÉS, Gerardo. Las dos fronteras de la democracia argentina. Buenos Aires: Homo Sapiens, 2001.

ALTAMIRANO, Carlos. La lucha por la idea: el proyecto de la Renovación peronista. In: NOVARO, Marcos; PALERMO, Vicente (Ed.). Historia reciente. Argentina en democracia. Buenos Aires: Edhasa, 2004.

AUYER0, Javier. La política de los pobres. Las prácticas clientelares del peronismo. Buenos Aires: Ediciones Manantial, 2001.

BARROS, Sebastián. Orden, democracia y estabilidad. Córdoba: Alción, 2002. 
BORÓN, Atilio et al. Peronismo y menemismo: avatares del populismo en la Argentina. Buenos Aires: Ediciones El Cielo por Asalto, 1995.

CLOSA, Gabriela. Las transformaciones en el peronismo de Córdoba. In: TCACH, Cesar. (Coord.). Córdoba bicentenaria. Claves de su bistoria contemporánea. Córdoba: Centro de Estudios Avanzados, 2010.

DERRIDA, Jacques. Márgenes de la filosofía. Madrid: Cátedra, 1998.

DIARIO LA VOZ DEL INTERIOR, Córdoba, 1990.

FERRARI, Marcela. El peronismo en la historia reciente. Algunas interpretaciones. Revista Estudios de Filosofía Práctica e Historia de las Ideas, Mendoza, año 9, n. 10, p. 63-83, 2008.

FOUCAULT, Michel. Nacimiento de la biopolitica. Buenos Aires: Fondo de Cultura Económica, 2007.

LACLAU, Ernesto. Misticismo, retórica y política. Buenos Aires: FCE, 2006.

LACLAU, Ernesto. Nuevas reflexiones sobre la revolución de nuestro tiempo. Buenos Aires: Nueva Visión, 2000.

LACLAU, Ernesto; MOUFFE, Chantal. Hegemonía y estrategia socialista. Hacia una radicalización de la democracia. Buenos Aires: Fondo de Cultura Económica, 2004.

LARNER, Wendy. Neo-liberalism: policy, ideology, governmentality. Studies in Political Economy, Toronto, v. 63, p. 5-25, 2000.

LEIRAS, Marcelo. Todos los caballos del rey. La integración de los partidos políticos y el gobierno democrático de la Argentina, 1995 - 2003. Buenos Aires: Prometeo, 2007.

LEMKE, Thomas. Marx sin comillas: Foucault, la gubernamentalidad y la crítica del neoliberalismo". In: LEMKE T. et al. Marx y Foucault. Buenos Aires: Nueva Visión, 2006.

LEVITSKY, Steven. La transformación del justicialismo. Del partido sindical al partido clientelista, 1983 - 1999. Buenos Aires: Siglo XXI, 2005.

LEVITSKY, Steven. Una des-organización organizada: organización informal y persistencia de estructuras partidarias locales en el peronismo argentino. Revista de Ciencias Sociales, Buenos Aires, n. 12, p. 7-62, 2001.

MARTUCCELLI, Danilo; SVAMPA, Maristella. La plaza vacía. Las transformaciones del peronismo. Buenos Aires: Losada, 1997. 
MORENO y Senn ratifican su alejamiento de Bucco. La Voz del Interior Córdoba, 20 mayo $1998 . \quad$ Disponível em: <http://buscador.lavoz.com.ar/intervoz/98/05/20/pl_n5.htm>. Acesso em: 20 ago. 2013

MUSTAPIC, Ana María. Del partido peronista al partido justicialista. Las transformaciones de un partido carismático. In: CAVAROZZI, M. y ABAL MEDINA, J. M. (Comp.). El asedio a la política. Los partidos políticos en la era neoliberal. Rosario: Homo Sapiens, 2002.

PANEBIANCO, Angelo. Modelos de partido. Madrid: Alianza Editorial, 2009.

PEREYRA, Sebastián. Política y transparencia. La corrupción como problema público. Buenos Aires: Siglo XXI, 2013.

PUCCIARELLI, Alfredo. (Comp.). Los años de Menem. La construcción del orden neoliberal. Buenos Aires: Siglo Veintiuno, 2011.

REYNARES, Juan Manoel. La dimensión ideológica en el estudio de los partidos políticos. Una propuesta de lectura. Revista Trazos Universitarios, Santiago del Estero, 2012b. Disponible online en: $<$ http://revistatrazos.ucse.edu.ar/articulos_con_referato/ documents/Reynares140712.pdf>. Acesso em: 20 ago. 2013.

REYNARES, Juan Manoel. La identidad política de la renovación. El peronismo cordobés en la transición democrática. Villa María: Eduvim, 2012a.

SARTORI, Giovanni. Partidos y sistemas de partido. Madrid: Alianza, 1987. v. 1.

SIDICARO, Ricardo. Los tres peronismos. Estado y poder económico. Buenos Aires: Siglo Veintiuno, 2002.

WITTGENSTEIN, Ludwig. Investigaciones filosóficas. Barcelona: Altaya, 1999. 